\title{
Comparison of Filtering Algorithms for Rock Point Cloud Data
}

\author{
Sidong $\mathrm{LIU}^{1}$, Liang $\mathrm{HU}^{1}$, Tianxin $\mathrm{SHI}^{2}$, Jun $\mathrm{XIAO}^{1, \mathrm{a}}$, Ying WANG ${ }^{1}$ \\ ${ }^{1}$ University of the Chinese Academy of Sciences, China No.19A Yuquan Road, Beijing 100049 \\ ${ }^{2}$ Beijing University of Posts and Telecommunications, Beijing 100876 \\ aemail: xiaojun@ucas.ac.cn
}

\section{Keywords: Laser Scanning, Point Cloud, Filter, Performance Analysis}

\begin{abstract}
Over the past years, laser scanner has been frequently used in rock engineering. Several filters have been developed to extract bare-Earth points from point clouds while few filter for point cloud data of rock which is a special kind of point cloud. To find a suitable filtering method for rock points, a research is carried out to determine the characteristics and the performance of these filters and to identify directions for future research. In this paper, nine algorithms are analyzed qualitatively. Five of them are tested on the point cloud of rock and the performances are analyzed quantitatively. The performance of algorithms with local feature is better than others on average, but they have difficulty on filtering the root of vegetation which is close to the ground.
\end{abstract}

\section{Introduction}

Under the condition of current technology, the only plausible method of calculation and analysis for rock engineering is the numerical simulation. Laser scanner becomes more and more important in the application of rock engineering since its unique advantages. The raw point cloud data obtained by laser scanners are mixed with some noises such as vegetation and construction for the most part, so it is difficult to be used in the engineering calculations. Therefore, effective filter is essential for the calculations of rock engineering.

Rock can be divided into two parts as topsoil and bedrock. The surface morphology and the shape of rock are not all the same since the type of topsoil and bedrock are different. There is no specific algorithm for point cloud of rock as we know, so it has significant theoretical and practical value to carry out research on filtering problem for point cloud data of rock. A study to compare the performance of various filters is carried out, with the aim of:

1. summarizing the ideas and characteristics of existing algorithms,

2. comparing performance of existing filter algorithms using the point cloud of rock,

3. identifying the directions for future research on filtering point clouds of rock.

In pasted years, many researches about filtering algorithm of point cloud data have emerged and a lot of experts and scholars dedicated to improved methods of some classic filtering algorithms. Most of these improvements are carried out in allusion to the defects of an algorithm and only could enhance the performance for a particular aspect. The core bases of these algorithms are not changed in essence. Some classical filtering algorithms are compared in this paper to find a filtering algorithm which is suitable for rock data fundamentally.

\section{Filter Algorithms}

Each filter has an assumption about the structure of ground and non-ground points within a space, and the corresponding features are quantized to separate these points. Based on the features, the filters could be divided into three categories.

1. Base on Elevation values

These algorithms assume that objects are higher than ground in within a certain area and determine whether a point is ground by calculating the height difference. Morphological filter[1] rasterizes point cloud data and extracts the ground points by dilation and erosion on elevation values of a raster. On this basis, progressive morphological filter[2] preserves ground points and 
removes non-ground objects by gradually increasing the window size and using thresholds of elevation difference according to the window size. Maximum local slope filter[3] uses an inverted cone which is centered on the target point to remove the points whose slope is larger than threshold. Filter with moving window[4] generates an initial terrain surface composed by the lowest points with a moving window. Then the points in the surface are filtered if the elevation difference is larger than the threshold to generate a more accurate surface iteratively. Elevation threshold with expanding window filter[5] subdivides the dataset into an array of square cells and all points, except the minimum elevation, are discarded. After that, the threshold and the size of cells are increased iteratively, and all points whose elevation differences with the minimum are greater than a threshold are removed.

2. Based on additional information

These algorithms use various kinds of additional information acquired by the laser scanner to separate ground and non-ground points. Franceschi[6] proposed a method based on laser reflection intensity which is proportional to the reflectance of the target to distinguish marls and limestones. With the development of hardware technology, scanner returns multiple target echoes when acquiring the point cloud of object. Pirotti[7] selected ground candidates from the original points by taking into account the ordinal return number and the amplitude before progressive morphological filter. Lichti[8] exploited the four-channel (blue, green, red and near infrared) to present a method using supervised, parametric classification to assign thematic class labels to points.

3. Based on local feature

These algorithms assume that there are some differences in geometrical properties with a certain range. They try to of exhibit these properties in some geometric ways and separate ground and non-ground points using these properties. Progressively TIN (Triangulated Irregular Network) densification filter[9] derived a sparse TIN from minima of elevation within the neighborhood, and then adds points into the TIN iteratively to densify the point cloud progressively. In each iteration, a point is added if it meets certain criteria in relation to the triangle containing it that the distance from it to the triangle and the angles between it and vertices of the triangle are within a threshold. Vandapel[10] and Lalonde[11] introduced the concept of local dimensionality features to characterize the local 3D organization (point set is a line, a plane or 3D) of measured point. The eigenvalues of the PCA are used as ratios that are compared to three thresholds in order to define the feature space to separate the ground and navigation. This method is limited in appropriate spatial scale selection and Brodu[12] solved this problem by using multi-scale dimensional features.

\section{Qualitative Assessment}

Filters are built from combinations of different elements. From a study of above algorithms, four elements were identified.

Method of Calculating Feature-Features are quantized for later calculations and according to the effects of neighborhood on calculating feature value, the algorithms above are classified into three types as (1) feature value is calculated only according to the target point which is to be classified, (2) an original elevation surface is calculated and the elevation difference between target point and the elevation surface near it is used as the feature value, and (3) feature value of target point is calculated by a certain characteristic expressed by it and the rest point within a range of spatial neighborhood.

Single Step vs. Iterative-Some of these algorithms classify points at once while others classify points in multiple passes iteratively. The running-speed of the former is faster. The latter trades computational speed for accuracy and more information about the neighborhood of target point is gathered, so the performance of classification is better.

Removing vs. Replacement - In removing, a non-ground point is deleted from point cloud while a new point with different height replaces the filtered point. The former is typically found in algorithms that operate on irregularly spaced point clouds while the latter is typically found in algorithms that operate on rasterized point clouds. 
Dependence on Devices - Except coordinate information, some algorithms use additional information which is obtained by specialist equipment to filter points. These algorithms are dependent on devices, and application of them is limited by the dependence.

In view of the above characteristics, we have summarized the algorithms mentioned in section 2 and the details are shown in Table 1.

Table 1. Characteristics of filters

\begin{tabular}{|c|c|c|c|c|c|}
\hline Filter & $\begin{array}{l}\text { Feature(based } \\
\text { on) }\end{array}$ & $\begin{array}{l}\text { calculating } \\
\text { feature }\end{array}$ & iterative & $\begin{array}{l}\text { Deal with } \\
\text { filtered points }\end{array}$ & $\begin{array}{l}\text { dependence on } \\
\text { devices }\end{array}$ \\
\hline morphological filter & elevation & $\begin{array}{l}\text { with elevation } \\
\text { surface }\end{array}$ & yes & replacement & no \\
\hline $\begin{array}{l}\text { progressively TIN } \\
\text { densification filter }\end{array}$ & local feature & $\begin{array}{c}\text { with spatial } \\
\text { neighborhood }\end{array}$ & yes & removing & no \\
\hline $\begin{array}{l}\text { maximum local slope } \\
\text { filter }\end{array}$ & elevation & $\begin{array}{c}\text { with spatial } \\
\text { neighborhood }\end{array}$ & no & removing & no \\
\hline $\begin{array}{c}\text { filter with moving } \\
\text { window }\end{array}$ & elevation & $\begin{array}{l}\text { with elevation } \\
\text { surface }\end{array}$ & yes & removing & no \\
\hline $\begin{array}{l}\text { elevation threshold } \\
\text { with expanding } \\
\text { window filter }\end{array}$ & elevation & $\begin{array}{l}\text { with elevation } \\
\text { surface }\end{array}$ & yes & replacement & no \\
\hline $\begin{array}{l}\text { filter using intensity } \\
\text { data }\end{array}$ & $\begin{array}{l}\text { additional } \\
\text { information }\end{array}$ & Single point & no & removing & yes \\
\hline $\begin{array}{l}\text { filter using } \\
\text { multi-return }\end{array}$ & $\begin{array}{l}\text { additional } \\
\text { information }\end{array}$ & Single point & no & removing & yes \\
\hline $\begin{array}{c}\text { filter based on RGB } \\
\text { imagery }\end{array}$ & $\begin{array}{l}\text { additional } \\
\text { information }\end{array}$ & Single point & no & removing & yes \\
\hline $\begin{array}{l}\text { filter based on local } \\
\text { dimensionality feature }\end{array}$ & local feature & $\begin{array}{c}\text { with spatial } \\
\text { neighborhood }\end{array}$ & yes & removing & no \\
\hline
\end{tabular}

The feature of filters based on additional information is calculated only according to the target point. This kind of filters is completely data-driven, so they are independent of spatial sampling resolution. The additional information is closely related to the category of target objects. The situation of rock is very complex since the diversity of topsoil and bedrock, so the methods only using additional information are difficult to apply to rock points. For example, Kaasalainen[13] analyzed the influence of incident angle and distance, and the research shows that it is necessary to correct these two factors, and more research on roughness of surface, grain size of target object and other physical characteristics is needed. Filter based on RGB imagery is either not suitable for rock points since the limited separability of spectral signature of RGB components.

In addition, these filters are dependent on laser scanners, and the dependence limits their applications. But it is a viable solution to improve filtering accuracy by combining additional information and other methods.

Filters based on elevation value or local feature are not dependent on the devices, so they have better generalization. Most of them calculate the feature using the target point and some other points near it, so they are dependent on spatial sampling resolution. Most of the former calculate the height difference by generating an elevation surface. The performance of this method may be not very good in high steep slope, especially the side of rock. It is worth mentioning that, it is an effective method to solve the problem of scale selection by expanding the scale iteratively.

In dealing with the filtered points, most algorithms delete these points directly. It may lead to some holes, so recovering algorithms are needed. Morphological filter and elevation threshold with expanding window filter take the method of replacement, but both of them interpolate the adjacent grid elevation values simply. This method is a neighboring-region interpolation algorithm in a sense and there are some limitations when dealing with the holes of side. The performance of recovering gully covered by dense vegetation remains to be tested. These situations are often seen in point cloud of rock. 


\section{Quantitative Assessment}

As mentioned in the above section, there are some limitations in the filter only based on additional information, so only the filters based on elevation or local feature are evaluated in this section.

The errors in filter method are classified into two types: Type I Error which rejects rock points and Type II Error which accepts non-rock points. The result of filters can be seen in Table 2. The computed errors (over all the points) ranged from $10.50 \%$ to $51.08 \%, 7.25 \%$ to $74.13 \%$ and $5.26 \%$ to $42.70 \%$ for total, Type I and Type II errors. The algorithms based on elevation and cells have better performance for filtering objects and worse performance for steep slope terrain since the assumption that objects are higher than ground and neglect of discontinuities. The progressively TIN densification filter has poor performance for filtering objects. Filter based on local dimensionality feature is the best on average.

Table 2. Quantitative comparison.

\begin{tabular}{cccc}
\hline Algorithms & Total error(\%) & Type I error(\%) & Type II error(\%) \\
\hline $\begin{array}{c}\text { Morphological filter } \\
\text { progressively TIN } \\
\text { densification filter }\end{array}$ & 36.72 & 53.51 & 5.26 \\
$\begin{array}{c}\text { filter with moving window } \\
\text { elevation threshold with } \\
\text { expanding window filter } \\
\text { filter based on local } \\
\text { dimensionality feature }\end{array}$ & 25.96 & 17.02 & 14.07 \\
\hline
\end{tabular}

Based on previous experience and the results of experiments, the circumstances which the filter algorithms are likely to fail are classified into vegetation and discontinuity. The type II errors are caused by the former for the most part while type I errors by the latter.

The results of the algorithms mentioned can be seen in Table 3. There are three cases in which tall trees, low vegetation on flat and low vegetation on slopes.

Large vegetation - The size of this vegetation is very large. Because many of the filtering algorithms are localized, tall trees may not be filtered if the size of neighborhood is not big enough.

Low vegetation - It is more difficult for algorithms to differentiate between it and the ground because this kind of vegetation is closer to the ground.

Low vegetation in slope areas - It is similar to the problem of low vegetation in flat areas and complicated by steep slopes. If the terrain is small but sharp variations, the problem is complicated even further. 
Table 3. The effect of vegetation on filter performance.

\begin{tabular}{|c|c|c|c|c|c|c|}
\hline \multirow{2}{*}{ Algorithms } & \multicolumn{2}{|c|}{ Large vegetation } & \multicolumn{2}{|c|}{ Low vegetation } & \multicolumn{2}{|c|}{ Low vegetation on slopes } \\
\hline & Accuracy & main error & Accuracy & main error & Accuracy & main error \\
\hline $\begin{array}{l}\text { Morphological } \\
\text { filter } \\
\text { progressively }\end{array}$ & 99.80 & $\begin{array}{l}\text { a few ground } \\
\text { points }\end{array}$ & 98.87 & $\begin{array}{l}\text { a few ground } \\
\text { points }\end{array}$ & 80.00 & $\begin{array}{l}\text { ground } \\
\text { points }\end{array}$ \\
\hline $\begin{array}{c}\text { TIN } \\
\text { densification } \\
\text { filter }\end{array}$ & 93.79 & $\begin{array}{l}\text { root and low } \\
\text { vegetation }\end{array}$ & 73.99 & $\begin{array}{l}\text { root and low } \\
\text { vegetation }\end{array}$ & 51. 03 & $\begin{array}{c}\text { low } \\
\text { vegetation }\end{array}$ \\
\hline $\begin{array}{c}\text { filter with } \\
\text { moving } \\
\text { window }\end{array}$ & 98.97 & $\begin{array}{l}\text { A few ground } \\
\text { points }\end{array}$ & 46.21 & $\begin{array}{l}\text { both ground } \\
\text { and vegetation }\end{array}$ & 58.99 & $\begin{array}{l}\text { ground } \\
\text { points }\end{array}$ \\
\hline $\begin{array}{c}\text { elevation } \\
\text { threshold with } \\
\text { expanding } \\
\text { window filter }\end{array}$ & 95.99 & $\begin{array}{c}\text { root of } \\
\text { vegetation }\end{array}$ & 91.26 & $\begin{array}{c}\text { ground points } \\
\text { and a few } \\
\text { vegetation }\end{array}$ & 71.78 & $\begin{array}{c}\text { root of } \\
\text { vegetation }\end{array}$ \\
\hline $\begin{array}{l}\text { filter based on } \\
\text { local } \\
\text { dimensionality } \\
\text { feature }\end{array}$ & 98.97 & $\begin{array}{l}\text { A few ground } \\
\text { points }\end{array}$ & 85.10 & $\begin{array}{c}\text { root of } \\
\text { vegetation }\end{array}$ & 77.54 & $\begin{array}{c}\text { root of } \\
\text { vegetation } \\
\text { and a few } \\
\text { ground } \\
\text { points }\end{array}$ \\
\hline
\end{tabular}

All in all, morphological filter, elevation threshold with expanding window filter and filter based on local dimensionality feature do well in vegetation identifying. The performances of all the algorithms are good for large vegetation while progressively TIN densification filter and filter with moving window have difficulty in identifying low vegetation, especially on slopes. Since the plant roots are close to the ground, the misclassification of plant roots is a hard problem to solve completely.

Type I errors often happen at the discontinuities of rock which can be divided into two types as ridge and corner.

Sharp ridge - It is well known that rock is piecewise continuous and vegetation is filtered because they are discontinuous to terrain. So the discontinuities of rock may be filtered as object points.

Corner - It is similar but more drastic than ridge since the latter is intersection of two surfaces while the former is more than three surfaces.

The performances of filters mentioned are shown in Table 4. Morphological filter and elevation threshold with expanding window filter have difficulty at discontinuous. The performance of filter based on local dimensionality feature is significantly better than others. 
Table 4. Result at discontinuities.

\begin{tabular}{|c|c|c|c|c|}
\hline \multirow{2}{*}{ Algorithms } & \multicolumn{2}{|c|}{ Sharp ridge } & \multicolumn{2}{|c|}{ Corner } \\
\hline & Accuracy & main error & Accuracy & main error \\
\hline Morphological filter & 22.49 & steep-slope area & 18.80 & steep-slope area \\
\hline $\begin{array}{l}\text { progressively TIN } \\
\text { densification filter }\end{array}$ & 80.11 & $\begin{array}{c}\text { root and low } \\
\text { vegetation }\end{array}$ & 79.80 & $\begin{array}{l}\text { root and low } \\
\text { vegetation }\end{array}$ \\
\hline $\begin{array}{l}\text { filter with moving } \\
\text { window }\end{array}$ & 75.53 & $\begin{array}{l}\text { both ground and } \\
\text { vegetation }\end{array}$ & 67.88 & $\begin{array}{l}\text { both ground and } \\
\text { vegetation }\end{array}$ \\
\hline $\begin{array}{l}\text { elevation threshold with } \\
\text { expanding window } \\
\text { filter }\end{array}$ & 26.82 & steep-slope area & 25.64 & steep-slope area \\
\hline $\begin{array}{l}\text { filter based on local } \\
\text { dimensionality feature }\end{array}$ & 90.13 & $\begin{array}{l}\text { some vegetation } \\
\text { near corer }\end{array}$ & 93.40 & $\begin{array}{l}\text { some vegetation } \\
\text { near corer }\end{array}$ \\
\hline
\end{tabular}

\section{Conclusion}

The algorithms only using additional information are difficult to apply to rock points, but it is a viable solution to improve filtering accuracy using additional information as auxiliary information if scanner supports. The algorithms based on elevation have advantages for filtering vegetation, especial low vegetation but have limitations with the detail of side. It seems that the performance of algorithms with local feature is better than others on average, but they have difficulty on filtering the root of vegetation which is close to the ground.

The feature of target points is computed using the information in its neighborhood and it is an effective method to solve the problem of scale selection by expanding the scale iteratively. In each iteration, more information is computed so performance of classification is better. Some algorithms recover the holes use a neighboring-region interpolation way, but there are some limitations when dealing with the holes of side. Special methods are needed to fill the holes.

\section{Acknowledgement}

This work is supported by the National Natural Science Foundation of China (No. 61471338), President Fund of UCAS, Youth Innovation Promotion Association CAS (2015361).

\section{References}

[1] Kilian J, Haala N, Englich M. Capture and evaluation of airborne laser scanner data[J]. International Archives of Photogrammetry and Remote Sensing, 1996, 31: 383-388.

[2] Zhang K, Chen S C, Whitman D, et al. A progressive morphological filter for removing nonground measurements from airborne LIDAR data[J]. Geoscience and Remote Sensing, IEEE Transactions on, 2003, 41(4): 872-882.

[3] Vosselman G. Slope based filtering of laser altimetry data[J]. International Archives of Photogrammetry and Remote Sensing, 2000, 33(B3/2; PART 3): 935-942.

[4] Petzold B, Reiss P, Stössel W. Laser scanning—surveying and mapping agencies are using a new technique for the derivation of digital terrain models [J]. ISPRS Journal of Photogrammetry and remote Sensing, 1999, 54(2): 95-104.

[5] Whitman D, Zhang K, Leatherman S P, et al. Airborne Laser Topographic Mapping: Applications to Hurricane Storm Surge Hazards[J]. Earth Science in the City: A Reader, 2003: 363-376. 
[6] Franceschi M, Teza G, Preto N, et al. Discrimination between marls and limestones using intensity data from terrestrial laser scanner[J]. Isprs Journal of Photogrammetry \& Remote Sensing, 2009, 64(6):522-528.

[7] Pirotti F, Guarnieri A, Vettore A. Ground filtering and vegetation mapping using multi-return terrestrial laser scanning[J]. ISPRS Journal of Photogrammetry and Remote Sensing, 2013, 76: 56-63.

[8] Lichti, D.D., 2005. Spectral filtering and classification of terrestrial laser scanner point clouds. The Photogrammetric Record 20 (111), 218-240.

[9] Axelsson P. DEM generation from laser scanner data using adaptive TIN models [J]. International Archives of Photogrammetry and Remote Sensing, 2000, 33(B4/1; PART 4): 111-118.

[10] Vandapel N, Huber D F, Kapuria A, et al. Natural Terrain Classification using 3-D Ladar Data[C]. IEEE International Conference on Robotics \& Automation. 2004:5117-5122.

[11] Lalonde J F, Vandapel N, Huber D F, et al. Natural terrain classification using three-dimensional ladar data for ground robot mobility[J]. Journal of Field Robotics, 2006, 23(10):839-861.

[12] Brodu N, Lague D. 3D terrestrial lidar data classification of complex natural scenes using a multi-scale dimensionality criterion: Applications in geomorphology[J]. Isprs Journal of Photogrammetry \& Remote Sensing, 2012, 68(1):121-134.

[13] Kaasalainen S, Jaakkola A, Kaasalainen M, et al. Analysis of Incidence Angle and Distance Effects on Terrestrial Laser Scanner Intensity: Search for Correction Methods[J]. Remote Sensing, 2011, 3(10):2207-2221. 